\title{
PATTERN OF HEARING LOSS IN PATIENTS OF CHRONIC KIDNEY DISEASE- A PROSPECTIVE COMPARATIVE STUDY
}

\author{
Souvagini Acharya ${ }^{1}$, Nirupama Pati², Anindita Arpita Nayak ${ }^{3}$ \\ ${ }_{1}^{1}$ Associate Professor, Department of ENT, VIMSAR, Burla. \\ ${ }^{2}$ Senior Resident, Department of ENT, VIMSAR, Burla. \\ ${ }^{3}$ Postgraduate Trainee, Department of ENT, VIMSAR, Burla.
}

\section{ABSTRACT}

\section{BACKGROUND}

Hearing loss in chronic kidney disease is believed to be of multifactorial aetiology. Associated hypertension and diabetes mellitus, use of ototoxic drugs, haemodialysis and the changes in metabolic parameters are the various reasons implicated in hearing loss. Also, the prevalence, degree and patterns of hearing loss associated with Chronic Kidney Disease (CKD) reported by various studies differ significantly.

The current study was conducted to assess the degree and type of hearing loss in CKD patients and to find out the association of duration of disease, haemodialysis and certain blood parameters with hearing loss.

\section{MATERIALS AND METHODS}

70 consenting patients of age 20 - 60 yrs. with Non-Syndromic Chronic Kidney Disease referred from Nephrology Department were divided into 2 groups of 35 each, those with hearing loss i.e. HL group and without hearing loss i.e. non-HL group. Their demographic details and duration of the disease were recorded. They were subjected to physical examination, blood investigations and pure tone audiometry. Both groups were studied on the basis of above parameters.

\section{RESULTS}

In the HL group, most patients (54.3\%) were shown to have mild degree of hearing loss and higher frequencies were mostly affected. In addition, there was a comparatively stronger association of hyponatraemia and hypokalaemia with HL group than with non-HL group. Mean duration of the disease and haemodialysis was higher in HL group than in non-HL group.

\section{CONCLUSION}

The patients of Chronic Kidney Disease have mild degree of hearing loss, mostly at higher frequencies. A longer duration of the disease and haemodialysis are directly related to the hearing loss. Nonetheless, low serum sodium and potassium has a stronger relation with hearing loss group than in non-hearing loss group.

\section{KEYWORDS}

Chronic Kidney Disease, Haemodialysis, Non-Syndromic, Sensorineural.

HOW TO CITE THIS ARTICLE: Acharya S, Pati N, Nayak AA. Pattern of hearing loss in patients of chronic kidney disease- a prospective comparative study. J. Evolution Med. Dent. Sci. 2017;6(47):3656-3659, DOI: 10.14260/Jemds/2017/788

\section{BACKGROUND}

Renal diseases have been associated with audiovestibular disorders for a considerable period of time. With the advent of haemodialysis and efficient drugs, renal patients live longer with a better quality of life. Such audiovestibular disorders become apparent during this time. Hearing loss is a more commonly reported finding than vestibular dysfunction.[1] Association of CKD with sensorineural hearing loss has been described by several studies in the past, although the basis for this has not been clearly established.[2,3] Certain studies have reported that the lesion in this form of hearing loss is found in the cochlea, $\left.{ }^{44}\right]$ while other studies have identified retrocochlear involvement in addition to cochlear pathologic abnormalities.[5] The general

Financial or Other, Competing Interest: None.

Submission 03-05-2017, Peer Review 01-06-2017,

Acceptance 07-06-2017, Published 12-06-2017.

Corresponding Author:

Dr. Souvagini Acharya,

Associate Professor,

Department of ENT,

VIMSAR, Burla-768017,

Sambalpur, Odisha, India.

E-mail: drs.acharya@yahoo.co.in

DOI: $10.14260 /$ jemds $/ 2017 / 788$ consensus in audiometric findings among patients with CKD claims a high frequency hearing loss with a notch at $6 \mathrm{kHz} .{ }^{6}{ }^{6}$ There are many similarities between the stria vascularis of the cochlea of the inner ear and the renal nephron at the ultrastructural level.

Both nephron and stria vascularis have epithelial structures and a vascular supply that are in close contact. In addition, basement membrane-lined intercellular channels exist in both the glomerulus and the stria.[7] These channels have enzymatic systems that depend on $\mathrm{Na}^{+} / \mathrm{K}^{+}$- adenosine triphosphates, and have carbonic anhydrase.[7] Different pharmacologic agents can cause both nephrotoxic and ototoxic effects. ${ }^{[8]}$ Furthermore, it has been shown that there is an immunological connection between the kidney and inner ear, in that antibodies raised against the nephron also deposit in the stria vascularis.[7] They may have a common antigenicity. ${ }^{[9]}$ Several potential mechanisms are implicated in hearing loss in CRF that have been postulated in literature including deranged haemoglobin, electrolytes, blood urea, serum creatinine, hypertension, ototoxic medication ${ }^{[10]}$ effects of the haemodialysis treatment itself,[11] plasma viscosity and vitamin D deficiency.[12] Hence, our study was directed at assessing the degree and type of hearing loss in 
CKD patients and to find out the association of certain blood parameters with hearing loss.

\section{MATERIALS AND METHODS}

Study Design- Observational study.

Centre of Study- VIMSAR, Burla. A tertiary care hospital.

Sampling- Simple random sampling.

\section{Inclusion Criteria}

Patients with non-syndromic chronic kidney disease in age group 20 - 60 yrs.

\section{Exclusion Criteria}

Patients of Chronic Kidney Disease with conductive hearing loss, history of ototoxic drug intake, endocrinopathies (Diabetes Mellitus, Hypothyroidism), infections (Otitis media, Syphilis, Tuberculosis, Mumps, Herpes zoster, Meningitis, Encephalitis), noise exposure, renal transplantation, or congenital hearing loss.

The study was conducted after approval from the Institutional Review Board in Department of ENT and Nephrology of VIMSAR, Burla during a period from October 2015 to September 2016; 118 patients with Non-Syndromic Chronic Kidney Disease were referred from Nephrology Department, VIMSAR, Burla for audiological evaluation; 22 patients not fulfilling the inclusion criteria were excluded from the study. Remaining 96 patients were subjected to pure tone audiometry and pure tone average was calculated; 42 patients had hearing loss (PTA $>25 \mathrm{~dB}$ ) and 54 patients were found to have normal hearing (PTA $<25 \mathrm{~dB}$ ) when measured at frequencies of 250,500,1000, 2000, 4000 and $8000 \mathrm{~Hz}$. Out of the 42 patients with hearing loss, 35 patients gave their consent for study and included in Hearing Loss (HL) group and 35 consenting patients with normal hearing were taken to form Non-Hearing Loss (Non-HL) group.

Hearing loss was further classified into mild (26-40 dB), moderate $(41-70 \mathrm{~dB})$, severe $(71-90 \mathrm{~dB})$ and profound (> $91 \mathrm{~dB}$ ) types at the different frequency ranges, i.e. low (250, $500 \mathrm{~Hz})$, mid $(1000,2000 \mathrm{~Hz})$ and high $(4000,8000 \mathrm{~Hz})$. Details of age, sex, mean duration of the disease and haemodialysis were recorded. Routine physical examination and blood investigations like blood urea, serum creatinine, serum $\mathrm{Na}^{+}$, serum $\mathrm{K}^{+}$and blood $\mathrm{Hb}$ were done for each patient.

Statistical analysis was done using SPSS version 15.0. Mean and Standard deviations were calculated for continuous variables and proportions for categorical variables. Student ' $\mathrm{t}$ ' test (two tailed, dependent) was used to find the significance of study parameters on a continuous scale within each group. Chi-square test was used to find the significance of study parameters on categorical scale between two or more groups. Microsoft Excel and Word was used to generate tables and pie charts and compare all the parameters between the two groups.

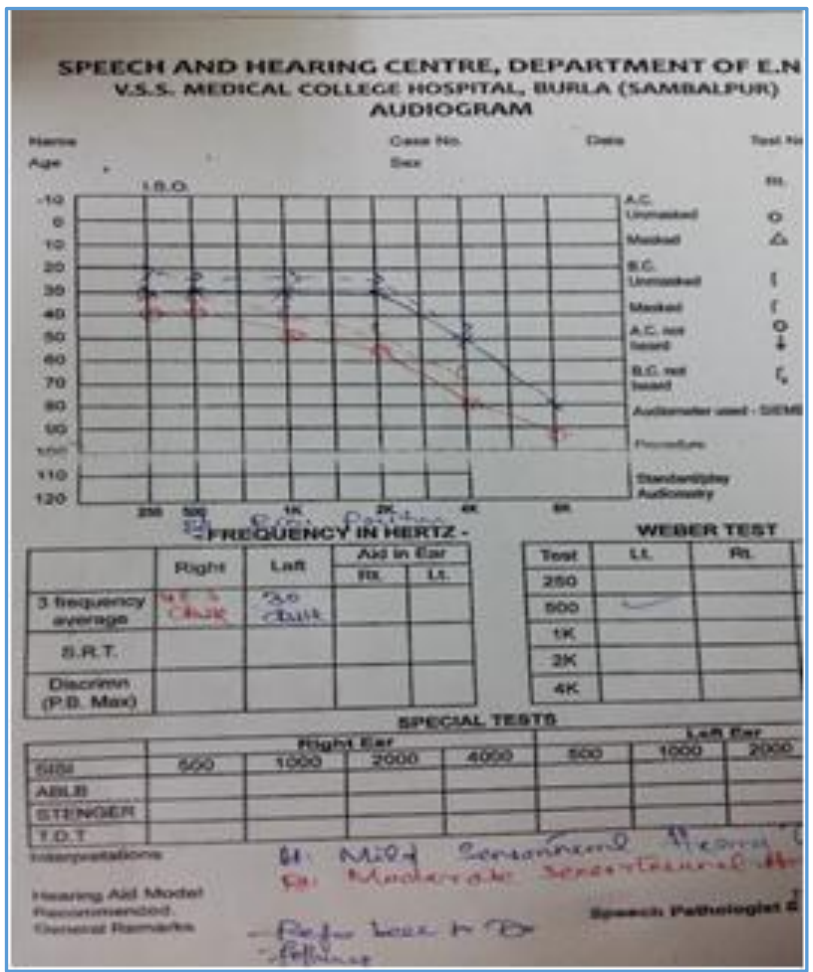

Pure Tone Audiogram of a Patient of Group 1 with Hearing Loss

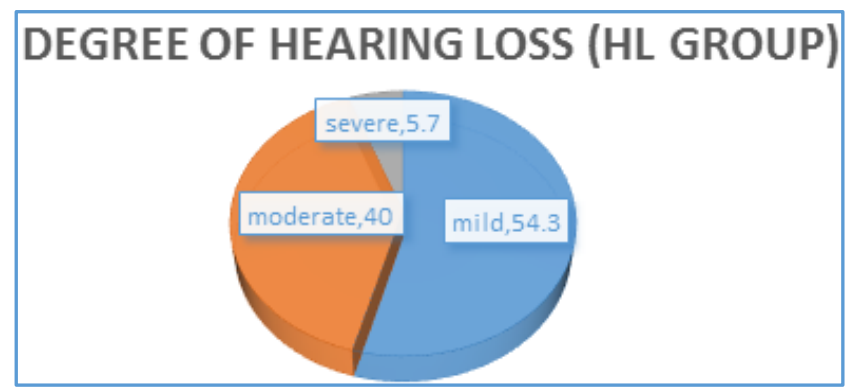

Graph 1. Degree of Hearing Loss (HL Group)

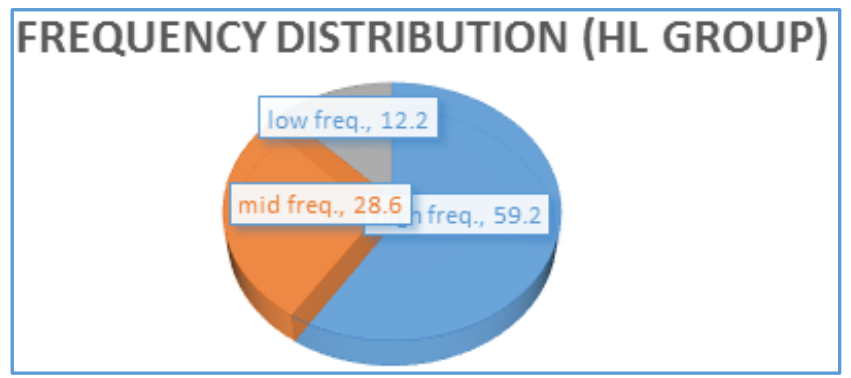

Graph 2. Frequency Distribution (HL Group)

\begin{tabular}{|c|c|c|c|}
\hline Parameter & HL Group & $\begin{array}{c}\text { Non-HL } \\
\text { Group }\end{array}$ & $\begin{array}{c}\text { Statistical } \\
\text { Significance }\end{array}$ \\
\hline Mean age (yrs.) & $\begin{array}{c}43.7 \\
(20-60)\end{array}$ & $\begin{array}{c}42.6 \\
(22-57)\end{array}$ & $\mathrm{Ns}$ \\
\hline Male: Female & $4: 1$ & $2: 1$ & $\mathrm{Ns}$ \\
\hline $\begin{array}{c}\text { Mean duration of CKD } \\
\text { (months) }\end{array}$ & $\begin{array}{c}32.6 \\
(6-70)\end{array}$ & $\begin{array}{c}25.8 \\
(4-66)\end{array}$ & $\begin{array}{c}\text { Yes, } \\
\text { P }<.00001\end{array}$ \\
\hline $\begin{array}{c}\text { Mean duration of } \\
\text { haemodialysis } \\
\text { (months) }\end{array}$ & $\begin{array}{c}30.2 \\
(4-65)\end{array}$ & $\begin{array}{c}22.4 \\
(4-60)\end{array}$ & $\begin{array}{c}\text { Yes, } \\
\text { P . .003 }\end{array}$ \\
\hline $\begin{array}{c}\text { Hypertension } \\
\text { (\%) }\end{array}$ & 63.6 & 68.2 & $\mathrm{Ns}$ \\
\hline
\end{tabular}




\begin{tabular}{|c|c|c|c|}
\hline Mean Hb (g/dL) & $\begin{array}{c}8.4 \\
(5.2-9)\end{array}$ & $\begin{array}{c}8.2 \\
(4.8-8.8)\end{array}$ & $\begin{array}{c}\mathrm{Ns} \\
\mathrm{P}=.145\end{array}$ \\
\hline $\begin{array}{c}\text { Mean blood urea } \\
(\mathrm{mg} / \mathrm{dL})\end{array}$ & $\begin{array}{c}142.6 \\
(40-350)\end{array}$ & $\begin{array}{c}134.2 \\
(44-327)\end{array}$ & $\begin{array}{c}\mathrm{Ns} \\
\mathrm{Ps} \\
(443\end{array}$ \\
\hline $\begin{array}{c}\text { Mean serum creatinine } \\
(\mathrm{mg} / \mathrm{dL})\end{array}$ & $\begin{array}{c}7.8 \\
(2.2-15.8)\end{array}$ & $\begin{array}{c}6.6 \\
(2.3-14.1)\end{array}$ & $\begin{array}{c}\mathrm{Ns} \\
\mathrm{P}=.105\end{array}$ \\
\hline $\begin{array}{c}\text { Mean serum sodium } \\
(\mathrm{mEq} / \mathrm{L})\end{array}$ & 122.4 & 141.6 & $\begin{array}{c}\text { Yes, } \\
\mathrm{P}<0.00001\end{array}$ \\
\hline $\begin{array}{c}\text { Mean serum potassium } \\
(\mathrm{mEq} / \mathrm{L})\end{array}$ & 4.4 & 4.8 & $\begin{array}{c}\text { Yes } \\
\mathrm{P}=.006\end{array}$ \\
\hline \multicolumn{3}{|c|}{ Table 1. Analysis of Clinical Parameters } \\
\hline
\end{tabular}

\section{RESULTS}

70 patients were included in our study and the mean age of patients in both the groups were similar being $43.7 \mathrm{yrs}$. in HL group and 42.6 yrs. in non-HL group. A male preponderance was seen in both groups with 4:1 ratio in first group and 2:1 in the second group. Mean duration of CKD and haemodialysis was higher in HL group, i.e. 32.6 and 30.2 months respectively than in non-HL group. A statistically significant higher mean duration of CKD and haemodialysis $(p<0.05)$ was found in HL group. Duration of CKD was found to have highly significant difference between two groups ( $\mathrm{p}<$ 0.001). Both serum sodium and potassium was lower in HL group than in non-HL group. However, the association of hyponatraemia with hearing loss was found to be highly statistically significant $(p<0.001)$. Blood urea and serum creatinine were higher in HL group than in non-HL group, but the difference was not much between the two groups. No apparent difference was noted in between the two groups regarding haemoglobin levels and hypertension.

In HL Group- 54.3\% had mild hearing loss, $40 \%$ had moderate hearing loss, $5.7 \%$ had severe hearing loss none had profound hearing loss, $12.2 \%$ had low freq. hearing loss, $28.6 \%$ had mid freq. hearing loss, $59.2 \%$ had high freq. hearing loss.

\section{DISCUSSION}

The incidence of sensorineural hearing loss among patients with CKD is considerably higher than in the general population.[12] Many factors like electrolyte disturbances, hypertension, ototoxic drugs ${ }^{[10]}$ effect of haemodialysis,[11] Vit D deficiency,[6,5] plasma viscosity, haemoglobin, serum creatinine and urea[13,11] have a bearing over the hearing loss in CKD patients. In fact Oda et al had even suggested a quantitative relationship between treatment, degree of impairment and temporal bone pathology.[14] In our study, we have encountered some of these factors. Bazzi et al found an incidence of $77 \%$ including patients with mild and very mild hearing loss. ${ }^{[13]} \mathrm{A}$ moderate-to-severe hearing loss was seen in $46 \%$ of the tested patients in a study by Ozturan et al.[6] It is in contrast to our study that reveals $54.3 \%$ patients having mild degree of hearing loss. Furthermore, our study shows that all frequencies are affected with high frequencies being more susceptible, i.e. $59.2 \%$. This is in contrast to the study by Gatland et al, who found 41 percent hearing impairment in low frequencies and 53 percent in high frequency range.[4] Though all frequencies can be affected in chronic renal failure, the susceptibility of high frequency to renal damage is well known,[15,16] which matched with our study. Accelerated presbycusis has been mentioned in the literature as a probable cause of hearing loss in patients with renal failure.[15] The audiometric pattern of the loss in old age varies from a sloping high tone loss to a flatter audiogram with a loss for all frequencies.[17] In assessment of clinical parameters, low serum sodium was found to have a strong correlation with hearing loss group. Chronic renal failure is characterised by disturbed $\mathrm{Na}^{+}$and $\mathrm{K}^{+}$blood levels. This may result in poor coupling of energy from the footplate of stapes to the hair cells.[18] In fact some researchers have suggested that the degree of hearing loss in CRF is directly related to the degree of hypernatraemia.[19] Similarly, Yassin et al found a correlation between hearing loss and hyponatraemia and suggested the possibility of a common defect in membrane transport of ions.[20] In our study, we found that both hyponatraemia and hypokalaemia has an association with hearing loss group, but association of hyponatraemia is more stronger than hypokalaemia.

The extension of life with the development of haemodialysis has brought new problems. Haemodialysis has been implicated both in the development of high frequency loss[17] and also in improvement of low frequency loss in CRF.[21] Though the role of dialysis is unclear, adverse factors possibly related to haemodialysis are acute hypotension, reduction in blood osmotic pressure, acute clearance of urea, increased red blood cell mass and immunologic reaction to dialyzer membranes.[22] Further, it has been proposed that long-term haemodialysis may cause electrolyte, osmotic and biochemical alterations leading to sensorineural hearing loss,[20] though a single session may not have significant effect on hearing. In a study by Erkoc et al, the mean duration of haemodialysis in the patient group with hearing loss was longer than that in the patient group without hearing loss. ${ }^{[5]}$ Mancini et al found no correlation between hearing loss, the duration of nephropathy and haemodialysis, suggesting that there must be another factor that caused hearing loss before treatment was started. ${ }^{[22]}$ But in our study we found that mean duration of the disease and haemodialysis were strongly related with hearing loss group than in non-hearing loss group.

Blood urea and serum creatinine levels were found to be higher in the group of patients in our study suffering from hearing loss. Uraemia affects the function of various organ systems and patients with chronic renal failure suffer widespread complications that are either the result of the chronic renal failure or the adaptive mechanism of the body in response to the disturbed homeostasis.[18]

Pathological changes in the cochlea range from mild loss of outer hair cells and spiral ganglion to complete absence of the organ of Corti. ${ }^{[12]}$ The presence of an unidentified uraemic toxin, which leads to uraemic nephropathy of the eighth cranial nerve leading to hearing loss has also been suggested.[14] Adler et al found a reduction in the $\mathrm{Na}^{+} / \mathrm{K}^{+}-$ adenosine triphosphates in the ears of uraemic guinea pigs and suggested that inhibition of this enzyme system may be a potential cause of $\mathrm{HL}$, as $\mathrm{Na}^{+}-\mathrm{K}^{+}$-activated ATPase in the cochlea is important for maintaining cationic gradients. They also reported an inverse correlation between serum creatinine levels and $\mathrm{Na}^{+}-\mathrm{K}^{+}$-activated ATPase.[7] Albertazzi et al documented the existence of 'uraemic neuropathy' as a possible cause for hearing loss in these patients.[23]

In our study, a definite relation between hypertension and mean haemoglobin with hearing loss could not be established. 


\section{CONCLUSION}

Hearing loss in CKD is mostly of mild degree and high frequency type. It is affected by the mean duration of the disease and haemodialysis, taking into account the various pathological processes involved in the disease. Patients with CKD are subjected to wide fluctuations in haemodynamic and metabolic parameters over time and the associated hyponatraemia; elevated blood urea and the internal homeostasis are all implicated in development of impaired hearing. Moreover, its early detection can prevent further progression of hearing loss. Modifications in treatment like restricted use of ototoxic drugs and haemodialysis can lead to minimise hearing loss that is anticipated in CKD patients.

\section{REFERENCES}

[1] Thodis C, Thodis E, Danielides V, et al. Hearing in renal failure. Nephrol Dial Transplant 2006;21(11):302330.

[2] Jakic M, Mihaljevic D, Zibar L, et al. Sensorineural hearing loss in hemodialysis patients. Coll Antropol 2010;34(Suppl 1):165-71.

[3] Vilayur E, Gopinath B, Harris DC, et al. The association between reduced GFR and hearing loss: a crosssectional population-based study. Am J Kidney Dis 2010;56(4):661-9.

[4] Gatland D, Tucker B, Chalstrey S, et al. Hearing loss in chronic renal failure-hearing threshold changes following haemodialysis. J Roy Soc Med 1991;84(10):587-9.

[5] Erkoc MF, Bulut S, Imamoglu H, et al. CT assessment of bone remodeling in the otic capsule in chronic renal failure: association with hearing loss. AJR Am J Roentgenol 2013;200(2):396-9.

[6] Ozturan 0 , Lam S. The effect of hemodialysis of hearing using pure-tone audiometry and distortion product otoacoustic emissions. ORL J of Oto Rhino laryngol 1998;60(6):306-13.

[7] Adler D, Fiehn W, Ritz E. Inhibition of $\mathrm{Na}+\mathrm{K}+-$ stimulated ATPase in the cochlea of the guinea pig. A potential cause of disturbed inner ear function in terminal renal failure. Acta Otolaryngol 1980; 90 (1-2):55-60.

[8] Quick CA, Fish A, Brown C. The relationship between cochlea and kidney. Laryngoscope 1973;83(9): 1469-82.

[9] Cosgrove D, Samuelson G, Meehan DT, et al. Ultrastructural, physiological, and molecular defects in the inner ear of a gene-knockout mouse model for autosomal alport syndrome. Hear Res 1998;121(12):84-98.
[10] Yassin A, Badry A, Fatthi A. The relationship between electrolyte balance and cochlear disturbances in cases of renal failure. J Laryngol Otol 1970;84(4):429-35.

[11] Serbetcioglu MB, Erdogan S, Sifil A. Effects of a single session of hemodialysis on hearing abilities. Acta Otolaryngol 2001;121(7):836-8.

[12] Di Paolo B, Di Marco T, Cappelli P, et al. Electrophysiological aspects of nervous conduction in uremia. Clin Nephrol 1988;29(5):253-60.

[13] Bazzi C, Venturini CT, Pagani C, et al. Hearing loss in short and long-term haemodialysed patients. Nephrol Dial Transplant 1995;10(10):1865-8.

[14] Oda M, Preciado MC, Quick CA, et al. Labyrinthine pathology of chronic renal failure patients treated with hemodialysis and kidney transplantation. Laryngo-scope 1974;84(9):1489-506.

[15] Nikolopoulos TP, Kandiloros DC, Segas JV, et al. Auditory function in young patients with chronic renal failure. Clin Otolaryngol Allied Sci 1997;22(3):222-5.

[16] Johnson DW, Wathen RL, Mathog RH. Effect of haemodialysis on hearing threshold. ORL J Otorhinolaryngol Relat Spec 1976;38(3):129-39.

[17] Borchgrevik HM, Tambs K, Hoffman HJ. The NordTrondelag Norway audiometric survey 1996-98: unscreened thresholds and prevalence of hearing impairment for adults $>20$ years. Noise health 2005;7(28):1-15.

[18] Glasscock ME, Shambaugh GE. Diagno-sis of ear disease. In: Glasscock ME, Johnson GD, (eds). Surgery of the ear. $4^{\text {th }}$ edn. Philadel-phia, W.B. Saunders Company 1990:55-84.

[19] Byrne JET, Kerr AG. Sensorineural hearing loss. In: Kerr AG, Booth JB, (eds). Scott-Brown's otolaryngology. $6^{\text {th }}$ edn. Oxford, Butterworth-Heinemann 1997:3/16/1-3/16/6.

[20] Meena RS, Aseri Y, Singh BK, et al. Hearing loss in patients of chronic renal failure: a study of 100 cases. Indian J Otolaryngol Head Neck Surg 2012;64(4): 356-9.

[21] Samir M, Riad H, Mahgoub M, et al. Transient otoacoustic emissions in children with chronic renal failure. Clinical otolaryngol Allied Sci 1998;23(1): 87-90.

[22] Mancini ML, Dello SL, Bianchi PM, et al. Sensorineural hearing loss in patients reaching chronic renal failure in childhood. Pediatr Nephrol 1996;10(1):38-40.

[23] Albertazzi A, Cappelli P, Di Marco T, et al. The natural history of uremic neuropathy. Contrib Nephrol 1988;65:130-7. 